\title{
Evaluation of the Senior Coal Mine Managers' Working Stress
}

\author{
Qi He ${ }^{1,2}$, Rong Guo ${ }^{2}$ and Jinsuo Zhang ${ }^{1,3 *}$ \\ ${ }^{1}$ School of Safety Science and Engineering, Xi'an University of Science and Technology, Xi'an, China \\ ${ }^{2}$ The Research Center of Energy Economics and Management, Xi'an University of Science and Technology, Xi'an, China \\ ${ }^{3}$ School of Economic and Management, Yanan University, Yan'an, China
}

\begin{abstract}
Coal mine ranks No.1 among the 6 major high-risk industries, so it is no doubt that the senior managers in the coal mine bear more stress than other industry executives. The massive working stress results in serious influences on the physical and mental health of the senior managers of coal mine, which might also induce the safety risk in the coal mine. Therefore, to evaluate the senior managers' working stress and put forward strategies of mitigating the stress is of great theoretical and practical significance in improving the physical and mental health of the senior managers and reducing the safety risk in the coal mine.

The research on the working stress has been made in the western countries for almost 50 years, China began the research in the mid and late 1990s, the research is spread across multiple industries including education, medical treatment, computer and aviation. However, there is little research on the senior managers' working stress of the coal mine, so the available literatures are few. In the paper, we, based on the working stress model of Robbins and through questionnaire survey, analyze the element composition of the senior managers' working stress of the coal mine; then, we construct the evaluation indicator system of the senior managers' working stress of the coal mine based on the individual factor, organization factor and environment factor; after that, we determine weights of each evaluation indicators by using the improved triangular fuzzy number weight method, and set up the evaluation model of the senior managers' working stress of the coal mine on the basis of the fuzzy comprehensive assessment method. At last, in accordance with the model, we evaluate and analyze the working stress for the senior managers of some typical coal mines, and diagnoses the major sources and intensities of the senior managers' working stress, and then propose corresponding strategies of mitigating the stress.
\end{abstract}

Keywords: coal mine, senior manager, working stress, evaluation model, mitigating strategies

\section{Background}

Coal mine ranks No.1 among the 6 major high-risk industries, as the senior managers, the physical and psychological stress they face so big that is unmatched by most of the other industries. The data released by the State Administration of work safety supervision and Administration is as follows: coal mines death numbers decreased from 6683 to 538, down by $91.95 \%$ from 2003 to 2017. Million tons death rate (DRPMT) decreased from 4.17 to 0.156 down by $96.26 \%$. Thus, the safety situation of china's coal mines improved in these years, but compared with the developed countries, the situation is still not optimistic, the safety level is still too low. For example, in the united states, the annual output of coal remained at about 10 tons over the past ten years, but DRPMT is only 0.03, far below our country. In such work environment, the senior managers for coal mine, as the direct responsibility of the coal enterprise, have to face the stress from many the safety production, government regulation, accident penalty and so on.

Under the dual stress for the inherent working stress and the particularity of industry, senior managers for coal mine often lost sleep, feel nervous, and even more appeared a variety of diseases, such as hypertension, heart disease and so on. The working stress that senior managers bears not only affect their own physical and psychological health, but also affect the development of the coal mine and business benefit. Evaluation for working stress is an important link in the study of working stress, after reviewing the relevant literature, we found that domestic scholar's study on working stress mainly focus on the relation between the working stress and stress reactions of such career, lack indepth theoretical research, seldom has creative theoretical results, can rarely be used in the China's special style enterprise management (Yang and Hu 2010). The theatrical and empirical study on senior managers for coal mine working stress is not enough, cannot grasp the true working stress bearded by senior managers for coal mine. So the evaluation for working stress to senior managers for coal mine is necessary.

\section{Investigation and Analysis on Working Stress for Senior Managers of Coal Mine \\ 2.1 Research object}

The senior managers are the one who is responsible for the organization, in coal mine organization, in this paper, the coal mine production management including barmaster, vice

* Corresponding Author: J.S. Zhang, mark56zhang@ 163.com

Copyright @ 2017 Canamaple Academia Services, http://press.camdemia.ca

DOI: 10.15273 /gree.2017.02.047 
barmaster, chief engineer, etc. The final sample of the study was the senior 59 managers, these managers' most graduated from college or university, mainly from 40 to 49 years old married men, more than 10 years' work experience.

\subsection{Questionnaire design}

The study collected data about the working stress for relative managers by questionnaire. The study used selfcompiled "working stress for senior managers of coal mine". The item design in this questionnaire referenced the relevant questionnaire of the study on the working stress. On the basis of the working stress model proposed by Robbins (1997), review the literature and have detailed discussion with experienced managers, after the preliminary survey of the questionnaire, analyze and revise, the 68 items of the question are finally fixed. The 6 items make statistics the basic information of the managers. The 17 items test the individual factors. The 18 items test the organizational factors. The 15 items test the environment factors. The 12 items test the stress reactions of senior managers, include the physical reaction and psychological reaction. The Likert grade scale is used to evaluate the question item, there are 5 grades from "Extremely inconsistent" to "Very consistent", the respondents will make a self-assessment according to the question item.

\subsection{The results of descriptive statistical analysis of working stress source factors}

The study based on the questionnaire, mostly adopt $\alpha$

Table 1. Average value and standard deviation for original factor for working stress to senior managers (in order of the average size).

\begin{tabular}{|c|c|c|}
\hline Factor & $\begin{array}{c}\text { Average } \\
\text { value }\end{array}$ & $\begin{array}{l}\text { Standard } \\
\text { deviation } \\
\end{array}$ \\
\hline F12 Industry status & 3.764 & 1.126 \\
\hline $\begin{array}{l}\text { F6 Work overload and safety } \\
\text { production }\end{array}$ & 3.635 & 0.872 \\
\hline F10 Operating stress & 3.415 & 0.844 \\
\hline F1 AB personality & 3.308 & 1.630 \\
\hline $\begin{array}{c}\text { F13 relevant policy and } \\
\text { legislation }\end{array}$ & 3.214 & 1.143 \\
\hline F7 Role Ambiguity & 3.190 & 1.159 \\
\hline $\begin{array}{c}\text { F8 lacking for organizational } \\
\text { support } \\
\end{array}$ & 3.187 & 0.882 \\
\hline F3 work ability and experience & 3.147 & 0.496 \\
\hline F2 self-quality & 3.012 & 1.159 \\
\hline F4 human relations & 2.985 & 0.665 \\
\hline $\begin{array}{c}\text { F9 generation for job } \\
\text { Insecurity } \\
\end{array}$ & 2.916 & 1.292 \\
\hline F11 production specification & 2.689 & 0.705 \\
\hline F14 social stability & 2.562 & 1.483 \\
\hline F5 heath condition & 2.485 & 1.338 \\
\hline Average number & 3.108 & \\
\hline
\end{tabular}

coefficient which is proposed by Cronbach (1951) as the Reliability measurement index of the management working stress questionnaire (Nunnally 1978). Reliability analysis results: Individual factor scale's (17 items) Cronbach's $\alpha$ coefficient is 0.684 , organizational factor scale's (18 items) Cronbach's $\alpha$ coefficient is 0.702 , the environmental factors scale's (15 items) Cronbach's $\alpha$ coefficient is 0.842 . Reliability analysis results show that the scale has a higher reliability. Revise and delete the items in each subscale by principal component analysis method, get the senior managers for coal mine working stress factors, totally get 14 working stress factors. The individual factors are F1-F5, the organizational factors are F6-F10, the environmental factors are F11-F14. After the Cronbach's $\alpha$ reliability test of the extracted stress source factor, and then has a descriptive statistics on the stress source factor to reflect its importance directly. The result is shown in Table 1.

Table 1 illustrates the overall level according to the study of coal mine senior managers working stress is higher, the mean of 3.108. Especially the F12 (industry) under the most stress, average of 3.764, with minimal stress F5 (health), mean value of 2.485 . In this work the stress source in 14, the differences are the smallest amount of F3 (ability to work and work experience), the largest is the F1 (AB personality).

\section{Determination of Evaluation Index Weights for Working Stress \\ 3.1 Establishment of evaluation index system for working stress}

According to this article the classification of the senior managers working stress source in coal mines, and through the principal component analysis to extract the source of job stress factors, build up the evaluation index system of coal mine senior managers working stress. the primary indicators of the index system including individual factor, organizational factor and environmental factors. the secondary indicators including F1-F14 totally 14 working stress factors. The individual factors are F1-F5, the organizational factors are F6-F10, the environmental factors are F11-F14.

\subsection{Establishment of index weights}

Generally, it is hard to give an accurate value when people make judgment on the important degree of an ambiguous concept or affair based on the knowledge and experience, while a floating region is often relatively easier. And the setvalued statistical method is born at the right moment for the quantitative analysis of problems difficult for quantification. As a result, the paper adopts the triangular fuzzy weighting method based on set-valued statistics to determine the indicator weight. At present, Chinese scholars Qi Qi (2014) and Si Shubin et al (2004) have studied the triangular fuzzy number theory respectively in the emergency management evaluation and risk investment fields. Based on their research thought and results, the paper has prepared a questionnaire to working stress for senior managers for coal mine evaluation indicator importance, invited 30 researchers 
in relevant fields to mark in the given intervals of $[0,10]$ for indicator importance to working stress for senior managers of coal mine evaluation indicator system and calculated the weight of each indicator. Due to limited space of the length, this text only takes the primary indicator "individual factor" as an example, which is shown in Table 2 .

Table 2. Set-valued statistical sample of primary indicator individual factor for working stress to senior managers.

\begin{tabular}{|c|c|c|c|c|c|}
\hline \multirow[t]{2}{*}{ Indicator } & \multicolumn{5}{|c|}{$\begin{array}{c}\text { Set of relevant scholars' evaluation } \\
\text { intervals }\end{array}$} \\
\hline & 7.0,8.5 & $4.0,5.0$ & $6.5,7.5$ & 7.0,8.0 & $6.0,7.0$ \\
\hline \multirow{5}{*}{$\begin{array}{l}\text { Individual } \\
\text { factor }\end{array}$} & $5.0,6.0$ & $7.0,8.0$ & $7.5,9.0$ & 7.0,7.5 & $7.5,8.0$ \\
\hline & $6.0,7.0$ & $5.5,6.5$ & $8.5,9.0$ & $6.5,8.0$ & $4.5,5.5$ \\
\hline & $6.0,7.5$ & $6.0,8.0$ & $6.5,8.0$ & $7.0,8.5$ & $8.0,8.5$ \\
\hline & $7.0,8.5$ & $5.0,6.0$ & $5.5,7.0$ & $5.0,7.0$ & $7.0,8.5$ \\
\hline & $6.5,8.0$ & $7.5,8.5$ & $8.0,9.0$ & $6.0,8.0$ & $7.0,8.0$ \\
\hline
\end{tabular}

The frequency $y_{i}^{\Lambda}=\mu\left(y_{i}\right)$ of the set $y_{i}$ included in interval sample is expressed by function as:

$$
y_{i}^{A}=\mu\left(y_{i}\right)=\left\{\begin{array}{ccc}
\frac{a_{1}}{L} & y_{i} \in\left[b_{1}, b_{2}\right) \\
\frac{a_{2}}{L} & y_{i} \in\left[b_{2}, b_{3}\right) \\
\vdots & \vdots \\
\frac{a_{1}}{L} & y_{i} \in\left[b_{1}, b_{l+1}\right) \\
\vdots & \vdots \\
\frac{a_{L}}{L} & y_{i} \in\left[b_{L}, b_{L+1}\right)
\end{array}\right.
$$

Thereby:

$$
y_{i}^{\wedge}=\mu\left(y_{i}\right)=\left\{\begin{array}{cc}
1 / 10 & y_{i} \in[4.0,4.5) \\
2 / 10 & y_{i} \in[4.5,5.0) \\
4 / 10 & y_{i} \in[5.0,5.5) \\
5 / 10 & y_{i} \in[5.5,6.0) \\
8 / 10 & y_{i} \in[6.0,6.5) \\
11 / 10 & y_{i} \in[6.5,7.0) \\
15 / 10 & y_{i} \in[7.07 .5) \\
15 / 10 & y_{i} \in[7.5,8.0) \\
8 / 10 & y_{i} \in[8.0,8.5) \\
3 / 10 & y_{i} \in[8.5,9.0)
\end{array}\right.
$$

Thereby, $\mathrm{a}_{1}=1, \mathrm{a}_{2}=2, \mathrm{a}_{3}=4, \mathrm{a}_{4}=5, \mathrm{a}_{5}=8, \mathrm{a}_{6}=11, \mathrm{a}_{7}=15$, $\mathrm{a}_{8}=15, \mathrm{a}_{9}=8, \mathrm{a}_{10}=3, \mathrm{~L}=10, \mathrm{~b}_{1}=4.0, \mathrm{~b}_{2}=4.5, \mathrm{~b}_{3}=5.0, \mathrm{~b}_{4}=5.5$, $b_{5}=6.0, b_{6}=6.5, b_{7}=7.0, b_{8}=7.5, b_{9}=8.0, b_{10}=8.5, b_{11}=9.0$.

The mean value and sample distribution variance for $\mathrm{y}_{\mathrm{i}}^{\Lambda}$ are applicable to the formula:

$$
\begin{aligned}
& \mathrm{E}\left(\mathrm{y}_{\mathrm{i}}\right)=\frac{\sum_{1=1}^{\mathrm{L}} \mathrm{a}_{\mathrm{l}}\left(\mathrm{b}_{1+1}^{2}-\mathrm{b}_{1}^{2}\right)}{2 \sum_{\mathrm{l}=1}^{\mathrm{L}} \mathrm{a}_{\mathrm{l}}\left(\mathrm{b}_{\mathrm{l}+1}-\mathrm{b}_{\mathrm{l}}\right)} \\
& \sigma^{2}=\frac{\sum_{\mathrm{l}=1}^{\mathrm{L}} \mathrm{a}_{1}\left\{\left[\mathrm{~b}_{l+1}-\mathrm{E}\left(\mathrm{y}_{\mathrm{i}}\right)\right]^{3}-\left[\mathrm{b}_{1}-\mathrm{E}\left(\mathrm{y}_{\mathrm{i}}\right)\right]^{3}\right\}}{3 \sum_{\mathrm{l}=1}^{\mathrm{L}} \mathrm{a}_{\mathrm{l}}\left(\mathrm{b}_{\mathrm{l}+1}-\mathrm{b}_{\mathrm{l}}\right)}
\end{aligned}
$$

Take the value into the formula and calculate the mean value $E\left(y_{i}\right)=7.014 "$ and the variance $\sigma^{2}=20.96 "$.

The calculated mean value $\mathrm{E}\left(\mathrm{y}_{\mathrm{i}}\right)$ is at the confidence interval at the confidence level of $95 \%$, take the sample variance $\sigma^{2}$ into the formula:

$$
\left[\mathrm{E}\left(\mathrm{y}_{\mathrm{i}}\right)-\frac{\sigma}{\sqrt{\mathrm{n}}} \mathrm{Z}_{\alpha / 2}, \mathrm{E}\left(\mathrm{y}_{\mathrm{i}}\right)+\frac{\sigma}{\sqrt{\mathrm{n}}} \mathrm{Z}_{\alpha / 2}\right]
$$

By looking up the table, the $Z_{\alpha / 2}$ in the formula is equal to 1.96 , and the interval end points can be calculated as:

$$
\begin{gathered}
\mathrm{E}\left(\mathrm{y}_{\mathrm{i}}\right)-\frac{\sigma}{\sqrt{\mathrm{n}}} \mathrm{Z}_{\alpha / 2}=7.014-\frac{\sqrt{10.48^{2}}}{\sqrt{30}} \times 1.96=3.262 \\
\mathrm{E}\left(\mathrm{y}_{\mathrm{i}}\right)+\frac{\sigma}{\sqrt{\mathrm{n}}} \mathrm{Z}_{\alpha / 2}=7.014+\frac{\sqrt{10.48^{2}}}{\sqrt{30}} \times 1.96=10.766
\end{gathered}
$$

[3.262, 10.766], which is the confidence interval of fuzzy evaluation indicator set $\mathrm{X}_{1}$ importance degree for "individual factor". Compared with the assignment by all researchers listed in Table 2, it is known 30 evaluation intervals are valid. The most probable value of indicator $\mathrm{X}_{1}$ importance is the mean value $\mathrm{E}\left(\mathrm{y}_{\mathrm{i}}\right)=7.01$. However the 30 interval end points listed in Table 2 respectively express the maximum and minimum for the importance evaluation on "individual factor" by researchers. Integrate the mean value, maximum and minimum and conclude the triangular fuzzy number $(7.0,7.01,8.5)$ for the indicator importance. Put them in the formula calculating the indicator's fuzzy comprehensive evaluation value $\tilde{\mu}_{\mathrm{i}}$ :

$$
\begin{aligned}
\tilde{\mu}_{\mathrm{i}} & =\left[\sum_{\mathrm{j}=1}^{\mathrm{k}} \mathrm{1}_{\mathrm{ij}}, \sum_{\mathrm{j}=1}^{\mathrm{k}} \mathrm{m}_{\mathrm{ij}}, \sum_{\mathrm{j}=1}^{\mathrm{k}} \mathrm{u}_{\mathrm{ij}}\right]+\left[\sum_{\mathrm{i}=1}^{\mathrm{n}} \sum_{\mathrm{j}=1}^{\mathrm{k}} \mathrm{1}_{\mathrm{ij}}, \sum_{\mathrm{i}=1}^{\mathrm{n}} \sum_{\mathrm{j}=1}^{\mathrm{k}} \mathrm{m}_{\mathrm{ij}}, \sum_{\mathrm{i}=1}^{\mathrm{n}} \sum_{\mathrm{j}=1}^{\mathrm{k}} \mathrm{u}_{\mathrm{ij}}\right]^{-1} \\
& \approx\left[\frac{\sum_{\mathrm{j}=1}^{\mathrm{k}} \mathrm{l}_{\mathrm{ij}}}{\sum_{\mathrm{i}=1}^{\mathrm{n}} \sum_{\mathrm{j}=1}^{\mathrm{k}} \mathrm{u}_{\mathrm{ij}}}, \frac{\sum_{\mathrm{j}=1}^{\mathrm{k}} \mathrm{m}_{\mathrm{ij}}}{\sum_{\mathrm{i}=1}^{\mathrm{n}} \sum_{\mathrm{j}=1}^{\mathrm{k}} \mathrm{m}_{\mathrm{ij}}}, \frac{\sum_{\mathrm{j}=1}^{\mathrm{k}} \mathrm{u}_{\mathrm{ij}}}{\sum_{\mathrm{i}=1}^{\mathrm{n}} \sum_{\mathrm{j}=1}^{\mathrm{k}} \mathrm{l}_{\mathrm{ij}}}\right] \mathrm{i} \in \mathrm{I}
\end{aligned}
$$

And obtain $\mathrm{X}_{1}$ importance's fuzzy comprehensive evaluation value $\tilde{\mu}_{i}, \mathrm{i}=1$.

$$
\tilde{\mu}_{1}=(0.286,0.340,0.400)
$$

The left and right expected values of $\tilde{\mu}_{i}$ can be expressed by formula as:

$$
\mathrm{I}_{\mathrm{L}}\left(\tilde{\mu}_{\mathrm{i}}\right)=\frac{\mathrm{l}_{\mathrm{i}}+\mathrm{m}_{\mathrm{i}}}{2} ; \mathrm{I}_{\mathrm{R}}\left(\tilde{\mu}_{\mathrm{i}}\right)=\frac{\mathrm{m}_{\mathrm{i}}+\mathrm{u}_{\mathrm{i}}}{2}
$$

If take $\eta$ as the coefficient, $\eta<0.5$ is optimistic coefficient, $\eta=0.5$ is neutral coefficient and $\eta>0.5$ is pessimistic coefficient, then the expected value of $\tilde{\mu}_{i}$ is formula 3.6, in which, the larger the $\mathrm{I}\left(\tilde{\mu}_{\mathrm{i}}\right)$ is, the larger the corresponding $\tilde{\mu}_{i}$ is. Here $\eta$ is 0.5 .

$$
\begin{aligned}
I\left(\tilde{\mu}_{i}\right)=\eta \frac{\mathrm{l}_{\mathrm{i}}+\mathrm{m}_{\mathrm{i}}}{2}+ & (1-\eta) \frac{\mathrm{m}_{\mathrm{i}}+\mathrm{u}_{\mathrm{i}}}{2} \quad 0 \leq \eta \leq 1 \\
=\frac{\mathrm{l}_{\mathrm{i}}+2 \mathrm{~m}_{\mathrm{i}}+\mathrm{u}_{\mathrm{i}}}{4} \quad \mathrm{i} & \in \mathrm{I}
\end{aligned}
$$

Put into formula (3.5) and (3.6) and conclude the expected value $I\left(\tilde{\mu}_{1}\right)=0.341$.

Then put $\mathrm{I}\left(\tilde{\mu}_{1}\right)$ into the formula (3.7) calculating the indicator weight $\omega_{\mathrm{i}}$, in which $\sum_{\mathrm{i}-1}^{\mathrm{n}} \omega_{\mathrm{i}}=1$.

$$
\omega_{\mathrm{i}}=\frac{\mathrm{I}\left(\tilde{\mu}_{\mathrm{i}}\right)}{\sum_{\mathrm{i}=1}^{\mathrm{n}} \mathrm{I}\left(\tilde{\mu}_{\mathrm{i}}\right)} \quad \mathrm{i} \in \mathrm{I}
$$

The weight $\omega_{\mathrm{i}}$ for the primary indicator "individual factor" is 0.33917 upon calculation. Likewise, calculate other indicator weights, as shown in Table 3.

\section{Evaluation Model Building for Working Stress 4.1 Model building}

Aiming at a large number of economic phenomena in reality have the characteristics of fuzziness, professor John scientists in the United States in 1960s founded the fuzzy comprehensive evaluation method. This method has both strict quantitative characterization, also hard to quantitative analysis of fuzzy phenomena can be subjective qualitative description, which combine qualitative description and quantitative analysis. Senior managers' working stress of coal mine involves multiple aspects of individual, 
organization, environment, these problems have certain fuzziness, the fuzzy mathematics theory is able to solve the uncertainty of system evaluation. Therefore, top management in coal mine with fuzzy comprehensive evaluation method of working stress intensity evaluation more reasonable.

Table 3. Index weight for working stress to senior managers.

\begin{tabular}{|c|c|c|c|}
\hline First level index & Index weight & $\begin{array}{c}\text { Second level } \\
\text { index }\end{array}$ & Index weight \\
\hline \multirow{5}{*}{$\begin{array}{l}\text { Individual } \\
\text { factor }\end{array}$} & \multirow{5}{*}{0.33917} & $\mathrm{~F} 1$ & 0.20124 \\
\hline & & $\mathrm{F} 2$ & 0.20656 \\
\hline & & F3 & 0.20473 \\
\hline & & $\mathrm{F} 4$ & 0.19012 \\
\hline & & F5 & 0.19735 \\
\hline \multirow{5}{*}{$\begin{array}{l}\text { Organizational } \\
\text { factor }\end{array}$} & \multirow{5}{*}{0.31704} & F6 & 0.19922 \\
\hline & & F7 & 0.20488 \\
\hline & & F8 & 0.20243 \\
\hline & & F9 & 0.19501 \\
\hline & & F10 & 0.19846 \\
\hline \multirow{4}{*}{$\begin{array}{l}\text { Environmental } \\
\text { factors }\end{array}$} & \multirow{4}{*}{0.34379} & F11 & 0.24389 \\
\hline & & F12 & 0.25475 \\
\hline & & F13 & 0.24952 \\
\hline & & F14 & 0.25184 \\
\hline
\end{tabular}

Based on the characteristics of evaluation index system of coal mine senior managers' working stress, this paper USES the multistage fuzzy comprehensive evaluation method to construct the evaluation model. The main steps summarized as follows:

Step 1, establishes the evaluation index set. Evaluation of the object is at all levels of index system of coal mine senior managers working stress indicators. Set $U=\left\{\mathrm{u}_{1}, \mathrm{u}_{2}\right.$, $\left.u_{3}\right\}$, then $u_{1}, u_{2}, u_{3}$ are the individual factors, environment factors and the matrix set of three indicators;

Step 2, evaluation set is established. To clearly describe the evaluation results may level, the evaluation sets by established is:

$$
\mathrm{V}=\left\{\mathrm{v}_{1}, \mathrm{v}_{2}, \mathrm{v}_{3}, \mathrm{v}_{4}, \mathrm{v}_{5}\right\}=\left\{\begin{array}{c}
\text { very large, } \\
\text { general }, \text { relatively large, } \\
\text { very small small, }
\end{array}\right\}
$$

Step 3, determine membership vector index evaluation, form a judgment matrix. As the "coal mine senior managers working stress questionnaire" based on the data obtained, the multi-item corresponding standard score and evaluation set, with each secondary index all the multi-item corresponding evaluation level, build the membership degree matrix of secondary indicators $R_{i}$.

$$
R_{i}=\left[\begin{array}{llll}
r_{i 11} & r_{i 12} & \ldots & r_{i 15} \\
r_{i 21} & r_{i 22} & \ldots & r_{i 25} \\
r_{i 31} & r_{i 32} & \ldots & r_{i 35}
\end{array}\right]
$$

Step 4, the establishment of index weight set. The index system of the present study includes two levels, in which the indicators of the superior indexes each are not identical. To bring into the weight distribution sets $\mathrm{A}=\left\{\alpha_{1}, \alpha, \alpha_{3}\right\}$, and that $\sum \alpha_{i}=1$. All levels of index set of weight allocation can be directly from the previous section to determine the index weight of the results.

$$
\begin{aligned}
& \mathrm{A}=\left\{\alpha_{1}, \alpha_{2}, \alpha_{3}\right\}, \quad \mathrm{A}_{1}=\left\{\alpha_{11}, \alpha_{12}, \alpha_{13}, \alpha_{14}, \alpha_{15}\right\}, \\
& \mathrm{A}_{2}=\left\{\alpha_{21}, \alpha_{22}, \alpha_{23}, \alpha_{24}, \alpha_{25}\right\}, \quad A_{3}=\left\{\alpha_{31}, \alpha_{32}, \alpha_{33}, \alpha_{34}\right\}
\end{aligned}
$$

Step 5 , the average vectors of $u_{1}, u_{2}, u_{3}$ will be determined one by one. The weight distribution sets $\left\{A_{1}\right.$, $\left.A_{2}, A_{3}\right\}$ corresponding to evaluation index set $U$ shall be transformed to the fuzzy evaluation vector for remark set $\mathrm{V}$, and set $B_{i}, i=1,2,3$, then

$$
B_{\mathrm{i}}=A_{\mathrm{i}} \cdot \mathrm{R}_{\mathrm{i}}=\left(\alpha_{\mathrm{i} 1}, \mathrm{\alpha}_{\mathrm{i} 2}, \mathrm{\alpha}_{\mathrm{i3}}\right)\left[\begin{array}{llll}
\mathrm{r}_{\mathrm{i} 11} & \mathrm{r}_{\mathrm{i} 12} & \ldots & \mathrm{r}_{115} \\
\mathrm{r}_{\mathrm{i} 21} & \mathrm{r}_{\mathrm{i} 22} & \ldots & \mathrm{r}_{\mathrm{i} 25} \\
\mathrm{r}_{\mathrm{i} 31} & \mathrm{r}_{\mathrm{i} 32} & \ldots & \mathrm{r}_{\mathrm{i} 35}
\end{array}\right] \mathrm{i}=1,2,3
$$

Step 6, calculating the membership matrix $\mathrm{R}_{\mathrm{Bi}}$ of primary index, namely the secondary index of the fuzzy comprehensive evaluation vector,

$$
\mathrm{R}_{\mathrm{Bi}}=\left[\begin{array}{l}
\mathrm{B}_{1} \\
\mathrm{~B}_{2} \\
\mathrm{~B}_{3}
\end{array}\right]=\left[\begin{array}{l}
\mathrm{A}_{1} \cdot \mathrm{R}_{1} \\
A_{2} \cdot \mathrm{R}_{2} \\
A_{3} \cdot \mathrm{R}_{3}
\end{array}\right] \quad \mathrm{i}=1,2, \quad 3
$$

Step 7, calculate the fuzzy comprehensive evaluation vector B for primary index U. Value corresponding to the evaluation set of vector B V mid-range membership degree. By the rule of maximum membership degree is the maximum of the vector $B$ reflects the coal mine high working stress for the diagnostic results.

$$
B=A \cdot R_{B i}=\left(a_{1}, \alpha_{2}, \alpha_{3}\right)\left[\begin{array}{l}
R_{B 1} \\
R_{B 2} \\
R_{B 3}
\end{array}\right]=\left(b_{1}, b_{2}, b_{3}, b_{4}, b_{5}\right)
$$

Step 8, calculate the intensity of working stress. B can only reflect the working stress for respondents belongs to a certain level. But if you want to two and more than two senior managers compares the intensity of working stress of coal mine, it must do further processing of the data. The particular way is as follows:

(1) To do the normalized processing for B to get B',

$$
B^{\prime}=\left(\frac{b_{1}}{\sum_{i=1}^{5} b_{i}}, \frac{b_{2}}{\sum_{i=1}^{5} b_{i}}, \frac{b_{3}}{\sum_{i=1}^{5} b_{i}}, \frac{b_{4}}{\sum_{i=1}^{5} b_{i}}, \frac{b_{5}}{\sum_{i=1}^{5} b_{i}}\right)
$$

(2) The percentage range corresponding to remark set $\mathrm{V}$ used for the description of assessment shall be expressed as respectively expressed as: if $\lambda \geq 90$, shows that the working stress to senior manager for coal mine is very large, and it needs to take immediate steps to alleviate it. If $80 \leq \lambda<90$, shows that the working stress to respondents is very large. In order to prevent the stress grows, they should be timely adjusting themselves to relieve stress. $70 \leq \lambda<80$ shows that the working stress to respondents is medium. If $60 \leq \lambda<70$, showing that the working stress to respondents is small. If $\lambda<60$, shows that the working stress to respondents is very small. It is important to note that stress not only can produce negative reaction, the appropriate stress to improve coal mine senior managers work enthusiasm, therefore, minimal stress is not good.

Finally, the median vector $\mathrm{M}$ is introduced into intervals on each score range, in which $\mathrm{M}=\{95,85,75,65,30\}$, then the acquired value for $\lambda=\mathrm{B}^{\prime} \cdot \mathrm{M}$ is the diagnostic results for working stress strength for senior managers for coal mine. It can be used to compare two evaluations and the size of the intensity of two or more individuals working stress. 


\subsection{Case analysis}

According to the working stress evaluation model for senior managers of coal mine, two senior managers came from Guyuan city, Ningxia were chosen as an example for comprehensive evaluation of working stress. The mine is a state-owned coal mine, have about 300 employees; Which is suitable for the mine $\mathrm{P} 1$, deputy party secretary, male, married, more than 50 years old, working for more than 30 years, college degree; The P2 for the mine's vice President, male, married, more than 40 years old, working for more than 20 years, specialist qualifications.

(1) To establish the evaluating index set for working stress to senior manager for coal mine.

$\mathrm{U}=\left\{\right.$ individual factor $\left(\mathrm{u}_{1}\right)$, organizational factor $\left(\mathrm{u}_{2}\right)$, environmental factor $\left.\left(\mathrm{u}_{3}\right)\right\}$;

(2) To establish the remark set.

$\mathrm{V}=\left\{\mathrm{v}_{1}, \mathrm{v}_{2}, \mathrm{v}_{3}, \mathrm{v}_{4}, \mathrm{v}_{5}\right\}=\left\{\begin{array}{c}\text { very large, } \\ \text { general }, \\ \text { relatively largely small, } \\ \text { very small }\end{array}\right\}$

(3) The questionnaire data on respondents P1, P2 shall be collected. It shall be statistic according to frequency for all corresponding indexes grade corresponding to evaluation set to form the membership degree vector, which constitute the membership degree matrix,

The secondary index membership matrix for P1 is:

$$
\begin{aligned}
\mathrm{R}_{\mathrm{P} 11} & =\left[\begin{array}{lllll}
0.67 & 0.00 & 0.33 & 0.00 & 0.00 \\
0.00 & 0.00 & 0.20 & 0.00 & 0.80 \\
0.00 & 0.17 & 0.17 & 0.33 & 0.17 \\
0.50 & 0.50 & 0.00 & 0.00 & 0.00 \\
1.00 & 0.00 & 0.00 & 0.00 & 0.00
\end{array}\right], \\
\mathrm{R}_{\mathrm{P} 12} & =\left[\begin{array}{lllll}
0.00 & 0.20 & 0.80 & 0.00 & 0.00 \\
0.00 & 0.50 & 0.50 & 0.00 & 0.00 \\
0.40 & 0.40 & 0.20 & 0.00 & 0.00 \\
0.00 & 0.00 & 0.25 & 0.50 & 0.25 \\
0.00 & 0.50 & 0.00 & 0.50 & 0.00
\end{array}\right], \\
\mathrm{R}_{\mathrm{P} 13} & =\left[\begin{array}{lllll}
0.20 & 0.00 & 0.60 & 0.00 & 0.00 \\
0.00 & 0.20 & 0.60 & 0.00 & 0.00 \\
0.00 & 0.50 & 0.50 & 0.00 & 0.00 \\
0.00 & 0.00 & 0.50 & 0.00 & 0.50
\end{array}\right],
\end{aligned}
$$

The secondary index membership matrix for $\mathrm{P} 2$ is:

$$
\begin{aligned}
\mathrm{R}_{\mathrm{P} 21} & =\left[\begin{array}{lllll}
0.00 & 0.00 & 0.33 & 0.67 & 0.00 \\
0.00 & 0.00 & 0.00 & 0.00 & 1.00 \\
0.00 & 0.00 & 0.17 & 0.66 & 0.17 \\
0.00 & 0.50 & 0.00 & 0.50 & 0.00 \\
0.50 & 0.00 & 0.50 & 0.00 & 0.00
\end{array}\right], \\
\mathrm{R}_{\mathrm{P} 22} & =\left[\begin{array}{lllll}
0.00 & 0.00 & 0.00 & 0.60 & 0.40 \\
0.50 & 0.50 & 0.00 & 0.00 & 0.00 \\
0.60 & 0.20 & 0.20 & 0.00 & 0.00 \\
0.00 & 0.75 & 0.25 & 0.00 & 0.00 \\
0.00 & 0.00 & 1.00 & 0.00 & 0.00
\end{array}\right], \\
\mathrm{R}_{\mathrm{P} 23} & =\left[\begin{array}{lllll}
0.25 & 0.00 & 0.00 & 0.75 & 0.00 \\
0.00 & 0.00 & 0.50 & 0.00 & 0.50 \\
0.00 & 0.00 & 0.50 & 0.50 & 0.00 \\
0.00 & 0.00 & 1.00 & 0.00 & 0.00
\end{array}\right]
\end{aligned}
$$

(4) Based on the weighing results on assessment index for working stress to senior manager for coal mine, it can be concluded that:

$$
\begin{aligned}
& A=\left\{\begin{array}{lll}
0.339, & 0.317, & 0.344
\end{array}\right\}
\end{aligned}
$$

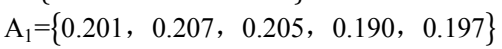

$$
\begin{aligned}
& \mathrm{A}_{2}=\left\{\begin{array}{llll}
0.199, & 0.205, & 0.202, & 0.196,0.198
\end{array}\right\}
\end{aligned}
$$

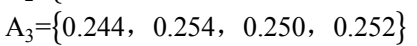

(5) The secondary fuzzy comprehensive evaluation vector for P1, P2 are calculated separately, is as follows:

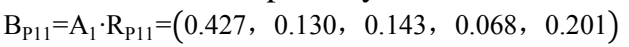

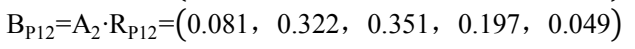

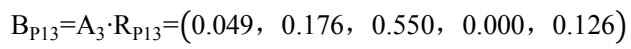

$$
\begin{aligned}
& \text { And, }
\end{aligned}
$$

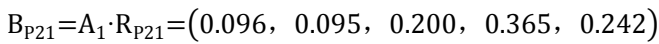

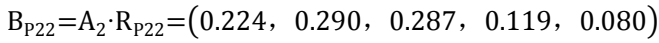

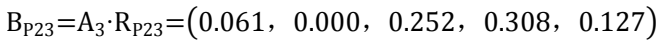

(6) The acquired secondary fuzzy comprehensive evaluation vector $\left\{B_{1}, B_{2}, B_{3}\right\}$ can be used as membership matrix $R_{B}$ of primary index, and for $\mathrm{P} 1$ and P2 are as follows:

$$
\begin{aligned}
\mathrm{R}_{\mathrm{P}_{\mathrm{B}}} & =\left[\begin{array}{l}
\mathrm{B}_{\mathrm{P} 11} \\
\mathrm{~B}_{\mathrm{P} 12} \\
\mathrm{~B}_{\mathrm{P} 13}
\end{array}\right]=\left[\begin{array}{lllll}
0.427 & 0.130 & 0.143 & 0.068 & 0.201 \\
0.081 & 0.322 & 0.351 & 0.197 & 0.049 \\
0.049 & 0.176 & 0.550 & 0.000 & 0.126
\end{array}\right] \\
\mathrm{R}_{\mathrm{P} 2 \mathrm{~B}} & =\left[\begin{array}{l}
\mathrm{B}_{\mathrm{P} 21} \\
\mathrm{~B}_{\mathrm{P} 22} \\
\mathrm{~B}_{\mathrm{P} 23}
\end{array}\right]=\left[\begin{array}{lllll}
0.096 & 0.095 & 0.200 & 0.365 & 0.242 \\
0.224 & 0.290 & 0.287 & 0.119 & 0.080 \\
0.061 & 0.000 & 0.252 & 0.308 & 0.127
\end{array}\right]
\end{aligned}
$$

(7) To calculate the fuzzy comprehensive evaluation vector for primary index of working stress on P1 and P2, respectively;)

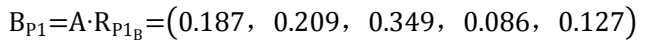

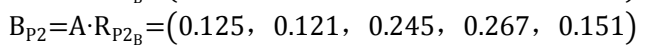

The specific data in these two vectors reflect the intensity of working stress and membership degree. Corresponding to each degree in the remark set V for P1, P2. Then according to the rule of maximum membership degree, the intensity of working stress for P1, P2 can be acquired, namely the remark corresponding to maximum in vector.

This method can evaluate the coal senior managers intensity of working stress, but if you want to two or more than two people comparing a horizontal stress levels and needs of the data for further processing.

(8) The further quantification for evaluation result on working stress; the vector $\mathrm{M}=\{95,85,75,65,30\}$ shall be calculated according to the assigned numerical range for remark set $\mathrm{V}$ to find out its median, then the final evaluation results for working stress to $\mathrm{P} 1$ and $\mathrm{P} 2$ senior managers for coal mine are as follows:

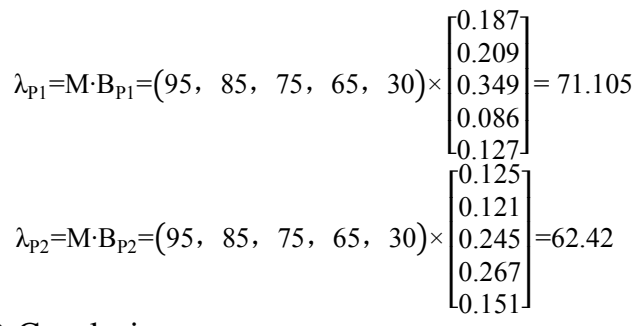

(9) Conclusion

The following results can be obtained to according to calculating results for $\mathrm{P} 1, \mathrm{P} 2$ working stress:

P1 stress evaluation comprehensive score of 71.105 , general strength. By the calculation process, the P1 from individual factors working stress is very big, but because of the strength of the stress from organizational factors and environmental factors is generally, therefore, the total stress strength of P1. Go deep into the individual factors of secondary index score, found that the stress mainly comes from $\mathrm{AB}$ personality, relationships and health. Alleviate the working stress for P1 should, therefore, mainly from the individual level to respond effectively to the strategy of the three aspects, organization and family and friends to give corresponding support. P1's working stress also has a certain relationship with age and position, because of the 
party committee deputy secretary general is mainly responsible for coal mine construction of ideological and political work, and he has the year lead half hundred, physical condition may have high strength is not enough to load work tasks.

P2 intensity of working stress is lower than P1, the evaluation of the comprehensive score of 62.42 , stress strength is small. The computation shows that the P2 from organizational factors intensity of working stress is big, but due to stress from the individual and the environment is small, so overall, stress strength is small. Go deep into the organizational factors found secondary index score and its stress mainly to role ambiguity and lack of organizational support. Appropriate working stress is helpful to improve work enthusiasm, ease if persisted in, should start from the two aspects of organizational level. P2 as the mine's deputy prevention, main responsibility is in under the leadership of the general, cling mineral "one pass and three prevention "work on the three prevention". The coal mine sets a chief engineer, seven deputy chief engineers, including general prevention, electrical and mechanical, mining and so on, so their jobs are constrained by the higher level peace at the same time.

\section{Discussion}

Research has shown it is very necessary to explore and implement some effective mitigation strategy. Based on the primary index on for working stress to senior managers of coal mine above motioned, the stress mitigation strategy shall be presented with the three aspects: of individual, organization, and environment.

\subsection{Remedial measure based on individual aspects}

From the individual level, the senior manager for coal mine as the main body suffered from stress is the first to know if fall into high working stress. Therefore, they should think of some way to alleviate the working stress and reduce the adverse influence on themselves by working stress from the perspective of their own. Firstly, accept the existence of working stress and made an effort to adjust the mentality to form a positive and optimistic attitude to face life. Secondly, through the body relax, get rid of bad habits to achieve the purpose of relieving stress. Such as the stress management expert Adamson (2008) came from USA strongly advocate a kind of based on individual stress management idea "three strategy for stress management". Thirdly, constantly raise their ability to cope with stress. To maintain a positive attitude and a clear head, capture the causes and trends to high intensity stress, be good at seizing the moment and finally find the breakthrough point to solve the problem in time. Fourthly, make full use of social support (Wen 2000). In the usual life and work, we should pay attention to more communication with people, to enhance self-confidence and alleviate the working stress.

\subsection{Remedial measure based on organizational aspects}

From the organizational aspects, a complete working stress management system can be built. the management mechanism on working stress should include four sections such as early warning, diagnosis, control and intervention in.

Working stress warning, i.e. perceived job stress signals in a timely manner can provide a basis for subsequent diagnosis of stress intensity. The diagnosis of working stress is a process that further confirms the intensity and sources of working stress after the senior managers of coal mine whose working stress has been discovered by organization. The control of working stress, that is a process that adopts corresponding strategies to alleviate stress after the senior managers of coal mine whose working stress has been diagnosed by organization. Working stress intervention is also a kind of control, its particularity lies in the fact that when the coal mine senior managers working stress is too high, to lead to radical thinking, confusion, emotional ups and downs fluctuation is large, deal with the problem is too hasty, and the general control measures is invalid, organization will need to be forced intervention to solve the problem.

\subsection{Remedial measure based on environmental aspects}

From the environment level, it is necessary to give full play to the power of the state to effectively mitigate the stress to senior managers for coal mine from industry particularity and market condition. For example, to improve the safety laws and regulations on coal production, adjust the tax policy to reduce burden of enterprises. In order to inhibit the stress from the sources, it is necessary to strictly control the approval and production, for coal mine with poor condition on production safety, such as with conditions of difficult mining technology, complicated geological condition, low production and high gas content.

\section{References}

Adamson, E., 2008. Stress management book. Harbin, Heilongjiang Science and Technology Press.

Li, L. and Q. She, 2009. The relationships among nurses occupational stress, type-A behavior pattern and subjective well being. Chinese Mental Health Journal, 23(4): 255 - 258.

Nunnally, J.C., 1978. Psychometrics methods. McGraw-Hill Company, New York.

Qi, Q., 2014. Study on evaluation and improvement of coal mine emergency management capacity. Xi'an Science and Technology University.

Robbins, S.P. and T.A. Judge, 1997. Organizational benavior. Beijing, China Renmin University Press.

Si, S., S.D. Sun, G.C. Han and J.Q. Wang, 2004. A weighted analysis of an integrated logistics support based on triangular fuzzy number. Journal of Northwestern Polttechnical University, 22(6): 689 - 694.

Wen, W.S., 2000. Research on the relationship between social support, psychological control and psychological health. Chinese Mental Health Journal, 14(4): 258 - 260.

Yang, L.F. and J.C. Hu, 2010. Analysis of job stress as moderator and mediator: taking job control model as an example. Soft Science, 24(7): 78 - 83. 